\title{
Die UN-Konferenz über Kakao
}

La Suisse et les négociations de l'accord international sur le cacao

Andràs November

\section{OpenEdition}

\section{Journals}

Édition électronique

URL : http://journals.openedition.org/sjep/1045

DOI : 10.4000/sjep.1045

ISSN : 1663-9677

\section{Éditeur}

Institut de hautes études internationales et du développement

\section{Édition imprimée}

Date de publication : 1 janvier 1985

Pagination : 219-238

ISSN : 1660-5926

Référence électronique

Andràs November, « Die UN-Konferenz über Kakao », Schweizerisches Jahrbuch für Entwicklungspolitik [En ligne], 5 | 1985, mis en ligne le 16 février 2013, consulté le 08 septembre 2020. URL : http:// journals.openedition.org/sjep/1045; DOI : https://doi.org/10.4000/sjep.1045

Ce document a été généré automatiquement le 8 septembre 2020

(c) The Graduate Institute 


\title{
Die UN-Konferenz über Kakao
}

\author{
La Suisse et les négociations de l'accord international sur le cacao
}

Andràs November

\section{NOTE DE L'ÉDITEUR}

Zusammenfassung auf Deutsch. Volltext auf Französisch in Annuaire suisse de politique de développement: „La suisse et les négociations de l'accord international sur le cacao”, http://aspd.revues.org/1208.

\section{RÉSUMÉS}

Die UN-Konferenz über Kakao wurde mit dem Ziel einberufen, das 1980 abgeschlissene und seit 1982 suspendierte internationale Kakaoabkommen auf der Grundlage von Verhandlungen zu erneurrn, da die Preisschwankungen auf dem internationalen Kakaomarkt die verschiedenen Abkommen funftionsunfähig gemacht haben. Zur Stabilisierung des Kakaopreises sieht der Entwurf des Abkommens in seinen wesentlichen Punkten die Festlegung eines Priesbandes, die Errichtung eines Ausgleichslagers sowie zusätzliche Massnahmen (Marktrückzüge für die Kakaoüberschüsse) vor. Die Verhandlungen fanden zwischen Verbraucherländern und Produzentenländern statt. Die Verbraucherländer sind bereit, den Kakaopreis um einen Gleichgewichtspunkt herum zu stabilisieren, der für die Produzenten einträglich genug und gleichzeitig für die Absatzländer annehmbar wäre. Die Produzentenländer streben ihrerseits die Stabilisierung des Kakaopreises auf einem Niveau an, das für die wirtschaftliche Entwicklung erforderliche Einkünfte sichern Würde. Die Schweiz spielt bei den internationalen Verhandlungen über Kakao eine wichtige Rolle. Den wirtschaftlichen und politischen Interessen 
des Landes entsprechend, streben die schweizerischen Unterhändler den Abschluss eines funktionierenden Abkommens an. 